\title{
Self-help interventions for older smokers
}

\author{
Deborah J Ossip-Klein, Ann Marie Carosella, Deborah A Krusch
}

\begin{abstract}
Objective-To evaluate the relative effectiveness of two self-help smoking interventions as adjuncts to a self-help manual and telephone support service (hotline) for older smokers.

Design-Subjects were stratified on baseline variables and randomised to one of two treatment conditions in a methods development study.

Subjects-177 community-dwelling smokers aged 60 years and older.

Interventions-All subjects received a self-help manual and access to a smokers' telephone hotline. Subjects also received either mailings (Letters condition) or counselling telephone calls (Proactive condition) at four and eight weeks after enrolment.
\end{abstract}

Main outcome measures-Use of the hotline and prevalence of abstinence lasting at least 48 hours (verified by a "significant other") were assessed at three and six months for the full sample. Seven-day abstinence was calculated for comparison with previous research. A subsample of 91 subjects was followed up at 12 months.

Results-Overall abstinence rates for the two conditions were in the range of typical self-help interventions. Men were more likely to be abstinent than women at follow up at three and six months. A significant gender $\times$ treatment interaction was found, with abstinence rates higher for men in the Letters condition, and women in the Proactive condition. Hotline use was high, with nearly half of subjects calling by 12 months.

Conclusion-Both interventions appear promising for older smokers, but may be differentially effective for men and women. Older smokers will use a hotline; whether Letters and Proactive interventions can improve on manual and hotline effectiveness rates alone is being tested in a subsequent controlled trial.

Department of Community and Preventive Medicine and Cancer Center, University of Rochester Cancer Center, Rochester, New York, USA

Correspondence to: Dr DJ Ossip-Klein, Department of Community and Preventive Medicine and Cancer Center, University of Rochester Cancer Center, 601 Elmwood Avenue, Box 704, Rochester, New York 14642, USA; email: dossiklein@cc.urmc. rochester.edu
(Tobacco Control 1997;6:188-193)

Keywords: smoking cessation, aging, self-help

\section{Introduction}

Increased morbidity and mortality among older smokers have been clearly documented. ${ }^{1-3}$ Smoking is a major risk factor for seven of the top 14 causes of death in people aged 65 years and older, ${ }^{4}$ and has been related to a higher prevalence of conditions that disproportionately affect older persons, such as osteoporosis, ${ }^{5}$ cataracts, ${ }^{6}$ and macular degeneration, ${ }^{78}$ or to complications of these conditions. Smoking has also been related to increased symptoms, including coughing, difficulty breathing, tiring easily, and overall greater functional decline, for people aged 65 and older. ${ }^{910}$ Smoking cessation reduces risk of major diseases and improves survival ${ }^{1112}$ as well as quality of life. ${ }^{13}$ With the aging of the American population, older smokers represent an important target population for intervention.

Approximately 28\% Americans aged 50 and older smoke, ${ }^{10}$ with rates highest among those aged $50-65$ years $(32 \%$ and $27 \%$ for men and women, respectively). Even among Americans aged 65 and older, smoking prevalence rates are $17.2 \%$ and $13.7 \%$, respectively, for men and women. ${ }^{14}$ Older smokers have several unique characteristics that may influence quitting. They are more likely to report smoking-related symptoms and rate their health as poorer than that of their peers, which may enhance motivation to quit. ${ }^{16}$ In fact, diagnosis of myocardial infarction, stroke, or cancer has been related to subsequent smoking cessation in older adults. ${ }^{17}$ However, they are also less likely to believe in benefits of quitting and to engage in preventive healthcare..$^{15}$ Older smokers are also more likely to be longterm, heavy, nicotine-addicted smokers who are less confident of their ability to stop smoking. ${ }^{4}$ Older smokers are more likely to live alone, or, if married, to have a spouse who smokes, and to report that most of their friends smoke. ${ }^{16}$ Nevertheless, approximately $44 \%$ of smokers aged 50 and older want to quit, ${ }^{16}$ and the oldest smokers (65 and older) are more likely to be successful in quit attempts than are smokers aged 35-64. ${ }^{18}$

Few studies on effective smoking interventions in older smokers are available. Self-help interventions, which are more accessible than formal clinics to the population in general, seem particularly appropriate to older smokers whose greater physical limitations may preclude access to face-to-face services. Glynn, Boyd, and Gruman ${ }^{19}$ identified a set of recommended elements for self-help smoking interventions. These included using materials tailored to the needs of specific populations that address a range of stages of change ${ }^{20}$ in the cessation process, and using telephone support as an adjunct.

Telephone counselling appears to significantly increase cessation rates when used as an adjunct to self-help manuals. ${ }^{21}$ This has been demonstrated in large community trials using both reactive telephone support services (hotlines), where smokers call in to the hotline ${ }^{22}$ and proactive telephone counselling, where counsellors call subjects. ${ }^{23}$ Rimer and colleagues $^{24}$ examined the effects of telephone 
counselling specifically for mid-life and older smokers. In a controlled trial of 1553 smokers ages $50-75$, subjects received either a generic booklet on smoking cessation, a Clear horizons manual ${ }^{25}$ which was specifically tailored to this group, or a Clear horizons manual with two proactive telephone calls based on their stage of change. Abstinence rates at three months were significantly higher for Clear horizons plus proactive calls relative to the other two conditions $(10 \%$ vs $7 \%$ and $6 \%$ for Clear horizons plus proactive calls, Clear horizons alone, and the generic guide, respectively), although the added benefit of proactive counselling appeared to disappear in preliminary 12 month analyses. Thus, research on telephone support suggests the effectiveness of reactive and proactive telephone support for the general population of smokers, and at least an early benefit of proactive telephone counselling for mid-life and older smokers.

The current study was a methods development study ${ }^{26}$ to examine the relative effectiveness of two self-help interventions for older smokers, as adjuncts to a tailored self-help manual and reactive hotline. The goals were to determine use of the reactive hotline among older smokers, to develop adjunct interventions to be used in a subsequent larger controlled trial, and to examine differential effectiveness of interventions by gender. No hypotheses were posed regarding which intervention would be more effective, as prior comparisons of these combinations of modalities had not been tested.

\section{Methods}

SUBJECTS

Subjects were 177 smokers in Rochester, New York and immediately surrounding areas, who were recruited to join the "Smokers' Self-Help Project60" through advertisements in newspapers, and through television, radio, and newspaper interviews. Subjects met the following eligibility criteria: at least 60 years old, smoked at least 10 cigarettes/day for at least 10 years, planned to quit within the next three months, planned to stay in the area for the period of study, and lived in a home or apartment with access to a private telephone.

A total of 255 individuals requested information on the project. Of these, $179 \mathrm{com}$ pleted enrolment. One subject subsequently died, and a second did not receive project materials, resulting in a final sample of 177 subjects.

Subjects were stratified on four variables (gender; age grouping: $60-69,70-79$, and $\geqslant 80$ years; planned use of nicotine gum or patch; and daily cigarette consumption: 10-19, $20-29$, and $\geqslant 30$ cigarettes/day), and randomised to one of two treatment conditions.

\section{INTERVENTIONS}

\section{Intervention overview}

All subjects completed a baseline questionnaire and consent form, and received a copy of the Clear horizons self-help manual ${ }^{25}$ and a flyer inviting them to use the Freedom Line smokers' hotline. Subjects प्रुere then randomised to either a "Lotters" or "Proactive" treatment condition, amd received either two letters or two proactive counselling telephone calls over the subsequent three

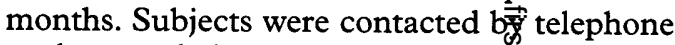
at three and six months to determine hotline use and smoking status.

Clear horizons manual

Developed at the Fox Chase Canger Institute (Philadelphia, Pennsylvania), the Clear horizons manual is tailored to smokers aged 50 and older. This manual is writtef at an eighth-grade reading level (13-149ुyear olds), with a large typeface and a? series of photographs and vignettes of imultiracial smokers in their fifties to seventides. Health messages focus on benefits of quittiong for older adults, and a range of tailored coping strategies for preparing to quit, quitting, and $\overrightarrow{\text { maintaining }}$ non-smoking. This manual has goen rated more favourably than a generi $\oplus_{\mathbb{D}}^{+}$cessation manual by older smokers. ${ }^{24}$

Freedom Line smokers' hotline

The Freedom Line was a community-based smokers' hotline, jointly operated by the Smoking Research Program at the University of Rochester and the Amerizan Lung Association-Finger Lakes Region Inc. This hotline was available 24 hours a day@seven days a week, and provided brief, $\rightarrow$ upportive messages, changed daily. In addition, during working hours from Monday to Friolay, callers were invited to hold on the line to. be put in touch with a counsellor. Counsellofs were all ex-smokers, trained to deliver a range of referral and intervention services. Freedgm Line as an adjunct to self-help manuals ${ }^{\circ}$ has been shown to enhance abstinence rates in a large population of rural smokers, with rates of use of $35.9 \%{ }^{22}$ This hotline is describe in greater detail elsewhere. ${ }^{22} 2728$

\section{Letters condition} At approximately four and eight $\stackrel{\circ}{\text { weeks after }}$ to call the hotline, along with brief messages of support from hotline counsellors. E\&h mailing also included either a telephone sitsicker with the hotline name and telephone number, or a "Quit Tips" card which listed the hotline number.

\section{Proactive condition}

At the same intervals as the Letter mailings, all subjects in the Proactive condition received two calls from Freedom Line counsillors. The counselling protocol was basedo on that developed by Rimer and colleague $\bar{\Omega}^{24}$ for use with older smokers. Counsellors followed a structured interview/intervention format to enquire about subjects' quit attemp迹, barriers to cessation, successes, and stage of change, ${ }^{20}$ and to provide motivational, cessation, and maintenance strategies based on stage of change. Counsellors also encouraged subjects to call the Freedom Line. 
MEASURES

Baseline

At enrolment, subjects completed a baseline questionnaire that assessed sociodemographic, health, and smoking-related variables. Subjects were also asked to provide the name of a "significant other" who could verify smoking status and locate the subject in the event of a move or telephone number change.

\section{Follow up}

All subjects were followed by telephone at three and six months after enrolment for determination of hotline use and smoking status. Subjects were paid $\$ 2.00$ for completion of each interview. In addition, the first 115 enrollees were called at 12 months for preliminary assessment of long-term outcomes. Subjects were not paid for the 12-month interviews, which were an addition to the funded study to obtain a preliminary look at overall abstinence rates by conditions at a long-term follow up.

The primary abstinence measure was prevalence of abstinence lasting at least 48 hours (" $48+$ hour abstinence prevalence"), with abstinence defined as "not even a puff of a cigarette" and no tobacco use for at least the past 48 hours. For purposes of comparison with other research, seven-day abstinence was also calculated. "Significant other" verification was obtained for self-reported abstinence. Subjects who refused follow up, refused "significant other" verification, or who dropped out were classified as smokers.

\section{Results}

SUBJECT CHARACTERISTICS

Table 1 summarises participant characteristics overall and by treatment condition. With the exception of the percentage smoking within 30 minutes of awakening, no significant differences were found between groups on baseline variables. Overall, $61.2 \%$ of subjects were women, about half were married $(54.9 \%)$, more than half had more than a highschool education $(60.9 \%)$, and most $(97.1 \%)$ were white. Subjects were generally heavy ( mean $=25.0$ cigarettes/day), long-term (median $=45$ years) smokers who were likely to smoke within 30 minutes of awakening $(84.9 \%$ vs $72.5 \%$ for Letters and Proactive subjects, respectively, $\chi^{2}(1)=4.00, P=0.045$ ).

Table 1 Subject characteristics

\begin{tabular}{|c|c|c|c|c|c|c|}
\hline \multirow[b]{2}{*}{ Characteristic } & \multicolumn{6}{|c|}{ Group } \\
\hline & $\begin{array}{l}\text { Letters } \\
n=85\end{array}$ & & $\begin{array}{l}\text { Proactive } \\
n=92\end{array}$ & & $\begin{array}{l}\text { Total } \\
n=177\end{array}$ & \\
\hline \multicolumn{7}{|l|}{ Demographics (\%) } \\
\hline Women & 62.1 & & 60.4 & & 61.2 & \\
\hline Married & 48.2 & & 61.1 & & 54.9 & \\
\hline More than high school education & 55.2 & & 66.3 & & 60.9 & \\
\hline White & 95.1 & & 98.9 & & 97.1 & \\
\hline \multicolumn{7}{|l|}{ Smoking history } \\
\hline Cigarettes/day (mean (SD)) & 24.2 & $(11.4)$ & 25.8 & $(12.1)$ & 25.0 & $(11.7)$ \\
\hline 24 -Hour quit episode past year (\%) & 53.2 & & 54.9 & & 54.0 & \\
\hline $\begin{array}{l}\text { Smoke within } 30 \text { minutes of } \\
\text { waking (\%) }\end{array}$ & 84.9 & & $72.5^{\star}$ & & 78.5 & \\
\hline Confidence rating $1-10$ (mean (SD)) & 5.4 & $(2.3)$ & 4.9 & $(2.5)$ & 5.1 & $(2.4)$ \\
\hline
\end{tabular}

Confidence rating $=$ confidence in ability to quit $(1=$ not at all to $10=$ extremely confident $)$. $\star \mathrm{P}<0.05$.
Most subjects had made prior quit attempts, with only $7.8 \%$ claiming that this was their first attempt, and $54.0 \%$ reported one quit episode lasting at least 24 hours during the past year. Subjects reported mid-range confidence ratings of their ability to quit (mean $=5.1$ on a 10 -point scale ranging from $1=$ "not at all confident" to $10=$ "extremely confident").

FOLLOW-UP COMPLETION RATES

A total of $98.9 \%$ of subjects were reached for follow up at three months (175/177), and $96.6 \%$ were contacted at six months (171/177). Those not contacted had either withdrawn from the project, or could not be contacted despite repeated attempts, and were considered smokers. At 12 months, $79 \%$ of targeted subjects were contacted (91/115). Of these, eight had disconnected numbers and were dropped from analyses, and 16 either refused or could not be contacted and were counted as smokers.

\section{HOTLINE USE}

By six months, $42.0 \%$ of subjects had called the Freedom Line at least once, and $17.5 \%$ of subjects had spoken to a counsellor during a hotline call. By 12 months, $50.5 \%$ of subjects reported calling the hotline at least once, and $24.5 \%$ reported speaking to a counsellor during a call.

Predictors of hotline use at six months were analysed with a series of simultaneous logistic regressions entering combinations of the following variables: gender, treatment condition, longest prior abstinence, daily cigarette consumption, smoking within 30 minutes of awakening, years smoked, and confidence in ability to quit. The Hosmer-Lemeshow $\chi^{2}$ was not significant for any runs ( $P$ at least $>0.10$ ), demonstrating an adequate fit for the models. Results showed a significant effect only for gender (odds ratio $(\mathrm{OR})=2.24,95 \%$ confidence interval $(\mathrm{CI})=1.07$ to 4.69 ), with women significantly more likely to call the hotline. Subjects in the Letters and Proactive conditions did not differ significantly in hotline use.

PERCEIVED EFFECTIVENESS OF INTERVENTIONS Subjects were asked to rate the helpfulness of the manual, proactive calls or letters, and hotline on a 10-point scale, with 1 being not at all helpful and 10 being extremely helpful. No differences were found by condition or gender in ratings of helpfulness of the manual, with an overall mean rating of 6.9 (SD 2.4). Similarly, no differences were found in rating of hotline helpfulness, with overall mean ratings of 6.2 (SD 2.9) and 6.1 (SD 2.7) at three and six months, respectively, among hotline users. However, a significant gender effect was found for ratings of how helpful it was "just knowing the hotline was there" (assessed for non-users), with women providing more favourable ratings at both three months (mean $=5.6, \mathrm{SD} 3.0$ and mean $=4.2, \mathrm{SD} 3.2$ for women and men, respectively; $F(1,94)=4.84, \mathrm{P}=0.03$ ) and six months (mean $=5.1, \mathrm{SD} 3.3$ and mean $=3.8$, 
Table 2 Prevalence of abstinence (\%)

\begin{tabular}{lll} 
& \multicolumn{2}{l}{ Follow up } \\
\cline { 2 - 3 } & $\begin{array}{l}\text { Three months } \\
n=176\end{array}$ & $\begin{array}{l}\text { Six months } \\
n=177\end{array}$ \\
Measure & & \\
\hline Abstinent $\geqslant 48$ hours & & \\
$\quad$ Letters & 15.5 & 20.0 \\
$\quad$ Proactive & 14.1 & 19.6 \\
$\quad$ Total & 14.8 & 19.8 \\
Abstinent $\geqslant 7$ days & & \\
$\quad$ Letters \\
Proactive & 9.5 & 20.0 \\
$\quad$ Total & 14.1 & 19.6 \\
\hline
\end{tabular}

None of the between-group comparisons was statistically significant.

SD 2.9 for women and men, respectively; $F(1,120)=5.61, \mathrm{P}=0.02)$.

At three months, $13.4 \%$ of subjects remembered receiving one proactive call or letter, and $89.6 \%$ remembered receiving two proactive calls or letters. The Proactive condition was rated significantly higher than the Letters condition by both women (mean $=7.5$, SD 2.5 Proactive; mean $=6.3$, SD 2.8 Letters) and men $($ mean $=7.1$, SD 2.3 Proactive; mean $=$ 5.3, SD 3.0 Letters) $(F(1,145)=11.08, \mathrm{P}=$ $0.001)$. Overall, the project received a mean helpfulness rating of 5.8 (SD 2.7).

\section{SMOKING CESSATION}

Table 2 summarises abstinence prevalence (48+ hours and $7+$ days) by treatment condition. $\chi^{2}$ analyses showed no significant differences between conditions in abstinence rates, with overall $48+$ hour abstinence rates of $14.8 \%$ at three months and $19.8 \%$ at six months.

To examine the differential effects of treatment condition for men and women, logistic regressions were run for $48+$ hour abstinence prevalence at three and six months. The following variables were examined: gender, treatment condition, gender $x$ treatment interaction, and smoking within 30 minutes of awakening (to control for baseline differences). Results of these runs are presented in table 3. The Hosmer-Lemeshow $\chi^{2}$ was not significant for any runs ( $\mathrm{P}$ at least $>0.37$ ), demonstrating an adequate fit for the models. Significant main effects were found at three months for gender, with men significantly more likely to be abstinent $(17.9 \%$ vs $12.8 \%, \mathrm{OR}=0.20,95 \% \mathrm{CI}=0.06$ to 0.72 ) and condition, with abstinence rates higher in Letters condition $(15.5 \%$ vs $14.1 \%$, OR = $0.22,95 \% \mathrm{CI}=0.05$ to 0.91 ). In addition, a

Table 3 Prevalence of abstinence: gender $\times$ treatment effects

\begin{tabular}{|c|c|c|c|c|}
\hline \multirow[b]{2}{*}{ Measure } & \multicolumn{2}{|c|}{ Abstinent (\%) } & \multirow[b]{2}{*}{$O R$} & \multirow[b]{2}{*}{$95 \% C I$} \\
\hline & $\begin{array}{l}M e n \\
n=68\end{array}$ & $\begin{array}{l}\text { Women } \\
n=109\end{array}$ & & \\
\hline \multicolumn{5}{|c|}{ Three months } \\
\hline Letters & 30.0 & 7.4 & 12.50 & $1.91-81.46$ \\
\hline Proactive & 8.1 & 18.8 & & \\
\hline Total & 17.9 & 12.8 & 0.20 & $0.06-0.72$ \\
\hline \multicolumn{5}{|l|}{ Six months } \\
\hline Letters & 35.5 & 11.1 & 5.75 & $1.19-27.64$ \\
\hline Proactive & 16.2 & 21.8 & & \\
\hline Total & 25.0 & 16.5 & 0.25 & $0.08-0.77$ \\
\hline
\end{tabular}

$\overline{\mathrm{OR}}=$ odds ratios $\mathrm{CI}=$ confidence intervals significant gender $\times$ treatment interaction was found $(\mathrm{OR}=12.50,95 \% \mathrm{CI}=1.9 \Phi$ to 81.46$)$, with men more likely to be abstiont in the Letters condition $(30.0 \%$ vs $7.4 \%$ men and women, respectively), and women more likely to be abstinent in the Proactive्द्ध condition $(8.1 \%$ vs $18.8 \%$ for men and women, respectively). At six months, a signfficant main effect was found for gender only ( $\mathrm{Q} R=0.25$,

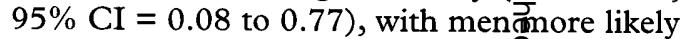
to be abstinent $(25.0 \%$ and $16.5 \%$ for men and women, respectively). Again, a signifficant gender $\times$ treatment interaction was fo $5.75,95 \% \mathrm{CI}=1.19$ to 27.64 ), withimen more likely to be abstinent in the Letters condition (35.5\% vs $11.1 \%$ for men and wongen, respectively) and women more likely to in the Proactive condition $(16.2 \%$ is $21.8 \%$ for men and women, respectively). The gender effect and gender $x$ treatment Interaction remained significant at both three and six months after controlling for the्D following additional variables in separate run? (to ensure adequate ratios of variables to sub ects): daily cigarette consumption, self-effic产y (confidence in ability to quit), anticipated support for quitting, living arrangement (ałone vs not alone), number of acquaintances who smoke (all/most $v s$ few/none), and marital status.

Additional exploratory analses were conducted to examine potential pedictors of abstinence, using variables that, based on theoretical models or empirical data or both, would be expected to be related to outcome. A series of logistic regression analyse ${ }^{3}$ were run, entering condition, gender, gुender $x$ condition, and one of the following variables per run (to ensure adequate ratios of variables to subjects): daily cigarette cossumption, smoking within 30 minutes of awakening, age grouping, self-efficacy (confidence ability to quit), anticipated support, living arrangement (alone $v s$ not alone), number of acouaintances who smoke (all/most $v$ s few/none), and marital status. Planned use of nicotine rèplacement was not examined, as only six subjects intended to use these products. None of the variables examined predicted abstinence at three months. Two variables were sognificantly related to abstinence at six monfifs: having no/few acquaintances who smoke $(\mathcal{O P}=0.21$; $95 \% \mathrm{CI}=0.04$ to 0.96 ), at higher

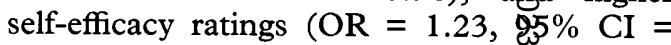
1.03 to 1.46 ).

At 12 months, for the subsample followed, abstinence prevalence rates were $13 \%$ for the Letters and $22.4 \%$ for the $\stackrel{+}{+}$ Proactive conditions. This difference was not \$latistically significant $(P=0.22)$; however, it ${ }_{\mathbb{T}}^{\text {should be }}$ noted that the sample size was colsiderably reduced, with only seven and 11 abstainers in the Letters and Proactive Eonditions, respectively.

\section{Discussion}

Our study was a methods developratent trial ${ }^{26}$ to evaluate the relative effectiveness of two selfhelp interventions for older smokers, with the goal of identifying interventions to test in a large, randomised, controlled trial. The results 
of this study suggest that the interventions are viable, as abstinence rates were in the range of those typically seen in self-help interventions. These results also compared favourably to the one other similar study by Rimer and colleagues with older smokers. ${ }^{24}$ The Proactive results were comparable across the two studies, although the subjects in the Rimer et al sample were somewhat younger (50-75). Abstinence rates $(7+$ days $)$ at three months in this latter study were $10 \%$ for the Proactive condition, compared with $14.1 \%$ in our study, and $7+$ day abstinence rates for both interventions in our study were higher than for the control condition in the study by Rimer et al $19.5 \%$ Letters and $14.1 \%$ Proactive for our study, $v s$ $6 \%$ and $7 \%$ Control for the Rimer et al study).

A significant gender $\times$ treatment interaction effect was found in our study, with men more likely to be abstinent in the Letters condition, and women more likely to be abstinent in the Proactive condition. These results were seen at follow up at three and six months; whether these differences would persist to 12 months is unknown, as the preliminary 12 -month sample was too small to assess gender $\times$ treatment effects accurately. In addition, high rates of hotline use were found, with $42 \%$ of the sample contacting the hotline by six months, and half calling by 12 months. These rates are higher than those reported in previous studies by our group and others, ${ }^{22} 2329$ and suggest that older smokers will use a smokers' hotline in perhaps greater numbers than their younger counterparts. Women were more likely than men to use the hotline, which is consistent with data that women are more likely to use healthcare and social support resources. ${ }^{30} 31$

Exploratory analyses suggested that having fewer acquaintances who smoke and higher self-efficacy are associated with abstinence at six months. Although consistent with previous studies, these results should be viewed as suggestive and in need of further testing in this population, as they emerged in the context of analyses of multiple variables, most of which did not yield significant results.

There were several limitations to our study. First, the sample size was considerably smaller than in previous trials. ${ }^{22-24}$ Although appropriate for methods development studies, clearly these findings need to be tested in a larger clinical trial. A second limitation was the relatively short follow up interval of six months, with only a subsample re-contacted for preliminary follow up. Again, this interval is acceptable for a methods development study and more extensive follow up was limited by pilot funding; however, longer term testing of these results is needed to examine whether differences persist. A final limitation is the lack of biochemical verification of smoking status, which was beyond the scope of our study. Previous work by our group and others has shown that patterns of treatment effects do not differ by whether abstinence has been verified biochemically or by "significant other", 22 although biochemical verification is recommended for a full, randomised, clinical study.
The overall effectiveness of an intervention may be defined by its clinical effectiveness (abstinence rates), as well as its public health reach (how wide a population it can reach), ${ }^{32}$ and its cost-effectiveness. The interventions used in our study - a self-help manual telephone hotline, series of mailings, and proactive telephone counselling-are approaches that can reach broad populations and geographical areas. In addition, they may be particularly suited for older smokers in that they do not require travel to another location for services. Preliminary analyses of the cost effectiveness of our project were conducted and will be reported separately.

We have previously demonstrated the effectiveness of a reactive hotline as an adjunct to a self-help manual in a large, geographically diverse population. ${ }^{22}$ The current study provides potential additional interventions to be tested in a large, controlled trial. Whether adding mailings or counselling telephone calls can improve on the "basic" manual plus hotline intervention is currently being tested in the United States in a large, multi-year 11-county trial of mid-life and older smokers

This research was funded in part by a pilot project grant from the Rochester Area Pepper Foundation/National Institute on Aging. Preparation of this manuscript was funded in part by National Cancer Institute Grant 1-RO1-CA67594.

1 LaCroix AZ, Lanag J, Scherr P, et al. Smoking and mortality among older men and women in three communities. $N$ among older men and women

2 Panginini-Hill A, Hsu G. Smoking and mortality among residents of a California retirement community. Am $\mathcal{F} P u b$ lic Health 1994;84:992-5.

3 US Department of Health and Human Services. The healt consequences of smoking: chronic obstructive lung disease. report of the Surgeon General. Rockville, Maryland: Public Health Service, Office on Smoking and Health, 1984. (DHHS Publication No (PHS) 84-50205.)

4 Orleans CT, Rimer BK, Cristinzio S, Keintz MK, Fleisher L. A national survey of older smokers: treatment needs of a growing population. Health Psychol 1991;10:343-51.

5 Hollenbach KA, Barrett-Connor E, Edelstein SL, Holbrook T. Cigarette smoking and bone mineral density in olde men and women. Am f Public Health 1993;83:1265-70.

6 Hankinson SE, Willett WC, Colditz GA, et al. A prospective study of cigarette smoking and risk of cataract surgery in women. $\mathcal{F} A M A$ 1992;268:994-8.

7 Christen WG, Glynn RJ, Manson JE, Ajani UA, Buring JE A prospective study of cigarette smoking and risk of age-related macular degeneration in men. $¥ A M A 1996$ 276:1147-51.

8 Seddon JM, Willett WC, Speizer FE, Hankinson SE. A prospective study of smoking and age-related macular degeneration in women. $\mathscr{f} A M A$ 1996;276:1141-6.

9 Nelson HD, Nevitt MC, Scott JC, Stone, K, Cummings SR. Smoking, alcohol, and neuromuscular and physical function of older women. $f A M A$ 1994;272:1825-31

10 Rimer BK, Orleans CT. Older smokers. In: Orleans CT, Slade J, eds. Nicotine addiction: principles and management. New York: Oxford University Press, 1993:385-95.

11 Hermansson B, Omenn GS, Kronmal RA, Gersh BJ. Beneficial six-year outcome of smoking cessation in older men and women with coronary artery disease: results from the CASS registry. $N$ Engl $f$ Med 1988;319:1356-69.

12 US Department of Health and Human Services. The health benefits of smoking cessation. A report of the Surgeon General, 1990. Rockville, Maryland: Public Health Service, Centers for Disease Control, Office on Smoking and Health, 1990. (DHHS Publication No (CDC) 90-8416.)

13 Fries JF, Green LW, Levine S. Health promotion and the compression of morbidity. Lancet 1989;1:481-3.

14 Novotny TE, Fiore MC, Hatziandreu E, Giovino GA, Mills SL, Pierce JP. Trends in smoking by age and gender: United States, 1974 1987 - the implications for disease impact. Prev Med 1990;19:552-61.

5 US Centers for Disease Control. Smokers' beliefs about the health benefits of smoking cessation-20 US communities, 1989. MMWR 1990;39:653-6.

16 Rimer BK, Orleans CT, Keintz MK, Cristinzio S, Fleisher L. The older smoker: status, challenges, and opportunities for intervention. Chest 1990;97:547-53.

17 Salive ME, Cornoni-Huntley J, LaCroix AZ, Ostfeld AM, Wallace RB, Hennekens CH. Predictors of smoking cessation and relapse in older adults. Am F Public Health 1992 82:1268-71. 
18 Hatziandreu RJ, Pierce JP, Lefkopoulou M, et al. Quitting smoking in the United States in 1986. F Natl Cancer Inst 1990;82:1402-6.

19 Glynn RJ, Boyd GM, Gruman JC. Essential elements of self-help/minimal intervention strategies for smoking cessation. Health Educ $Q$ 1990;17:329-45.

20 Prochaska JO, DiClemente CC. Stages and processes of self-change of smoking: toward an integrative model. $f$ Consult Clin Psychol 1983;51:390-5.

21 Lichtenstein E, Glasgow RE, Lando HA, Ossip-Klein DJ, Boles SM. Telephone counseling for smoking cessation rationales and review of evidence. Health Educ Res 1996;11:243-57.

22 Ossip-Klein DJ, Giovino GA, Megahed N, et al. Effects of a smokers' hotline: results of a 10 -county self-help trial. $\mathcal{f}$ Consult Clin Psychol 1991;59:325-32.

23 Orleans CT, Schoenbach VI, Wagner EH, et al. Self-help quit smoking interventions: effects of self-help materials, social support instructions, and telephone counseling. $\mathcal{f}$ inch 1991:59:439-48.

24 Rimer BK, Orleans CT, Fleisher L, et al. Does tailoring matter? The impact of a tailored guide on ratings and short-term smoking-related outcomes for older smokers. Health Educ $Q$ 1994;9:69-84.
25 Orleans CT, Rimer B, Fleisher L, Keintz MAA, Telepchak J, Robinson R. Clear horizons. Philadelphio Pennsylvania: Fox Chase Cancer Center, 1989.

26 Greenwald P, Cullen JW. The scientific appfoach to cancer control. $C A$ Cancer $\mathcal{F}$ Clin 1984;34:328-32

27 Ossip-Klein DJ, Shapiro RM, Stiggins J. Freedom Line: increasing utilization of a telephone support service for ex-smokers. Addict Behav 1984;9:227-30. $\Rightarrow$

28 Shapiro RM, Ossip-Klein DJ, Gerrity 负, Stiggins J Perceived helpfulness of messages on a community-based telephone support service for ex-smokers. Int $\mathcal{f}$ Addict telephone support

29 Glasgow RE, Lando H, Hollis J, Gilb LaChance P. A stop-smoking telephon helpline that nobody called. Am F Public Health 1993;830252-3.

30 Matthews KA. Are sociodemographic varialobes markers for psychological determinants of health? Pealth Psychol $1989 ; 8: 641-8$.

31 Cohen S, Syme SL. Social support and hequlth. Orlando, Florida: Academic Press, 1985.

$\overrightarrow{\overrightarrow{2}}$ health. Orlando,

32 Lichtenstein E, Glasgow RE. Smoking cessffiton: what have we learned over the past decade? $\mathcal{F}$ Const $1992 ; 60: 518-27$
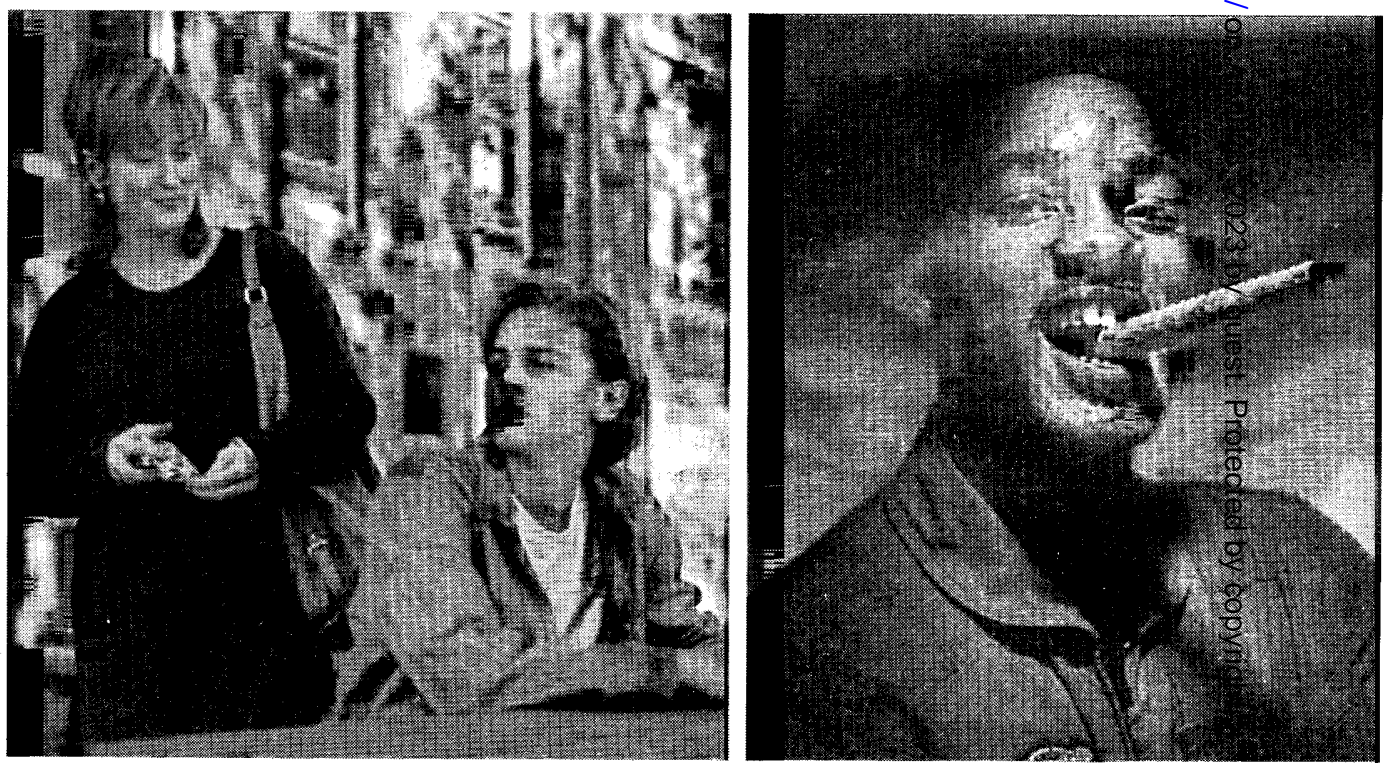

Smokes in the movies. Meryl Streep (left) in Marvin's Room, lighting up in front of co-star Leonardo DiCaprio, who plays her son. Will Smith (right), alien killer in the blockbuster movie Independence Day, smoked a cigar after he saved the world. Photograph of Will Smith by Andrew Brusso. 